\title{
Studies of the Mattson Shot Classifier
}

\section{By Raymond L. Blaine and Harold J. Valis}

\begin{abstract}
The size and distribution of peening and cleaning shot and sand particles of various shape characteristics were determined by use of a new apparatus and with a microscope and by microweighings. Tests indicated that the Mattson apparatus enabled a rapid visual evaluation to be made of size and distribution of shot and sand particles. A more precise evaluation can be made with the apparatus by determining the actual size distribution of the shot or other particles. This apparatus tends to determine the smallest dimension of particles that are irregular in shape and, when used with closely sized sieve fractions, makes possible an evaluation of the shape characteristics of the particles.
\end{abstract}

\section{Introduction}

In shot-peening, the energy with which the shot strikes the metal being treated must be carefully controlled. It is necessary to have the shot of uniform size, since differences in size or mass of the individual shot cause difficulties in regulating the intensities with which the shot strikes the metal part and unevenness in the peening operation.

The determination of particle size and the size distribution of materials have long been made with the aid of screens or sieves. When the sample contains a fairly wide range of sizes, the use of a series of closely sized sieves makes possible the determination of the size distribution of particles. However, when the particles are of nearly the same size, as with the peening shot, the information obtained from a series of sieves is inadequate to determine the size distribution. Another factor that is often important in measurements of granular materials is that of the shape of the particle. Some specifications (as for example ASTM D693-44, D694-44, D-556-40T, D557-40T, and D692-42 T) require certain particle shape characteristics but do not offer adequate apparatus or methods for evaluating this shape factor.

R. L. Mattson of General Motors Research Laboratory has developed an apparatus for rapidly determining the size and size distribution of peening shot. Although the apparatus offered a very rapid visual evaluation of both the size and distribution, information was desired as to the precision of the apparatus and the significance of the results. The simplicity of the apparatus and the principle on which it is based have suggested the possibility of its use for materials other than the peening and cleaning shot for which it was designed.

\section{Description of Apparatus}

The Mattson apparatus (see fig. 1) consists essentially of two plane sheets of glass separated at the two vertical edges by accurately ground metal wedges. Particles dropped into the space between the glass plates lodge at a point where the effective diameter of the particle and the distance between the plates are the same. An additional feature of the apparatus is a sample splitter, which is needed to reduce the sample to a suitable size.

The apparatus used in these studies consisted of 8 - by 10 -in. glass plates. The back plate was $\frac{1}{2}$ in. thick and reported by the manufacturer to be plane within 0.0005 in. The front plate was made of $3 / 16$-in. plate glass. The ground metal wedges, cemented to the front plate and separating the plates, were tapered at $0.010 \mathrm{~cm} / \mathrm{cm}$. The space between the plates was $0.25 \mathrm{~mm}$ at the bottom of the scale and $2.00 \mathrm{~mm}$ at the top, corresponding to the nominal openings of the No. 60 and the No. 10 sieves, ${ }^{1}$ respectively.

In order to remove the sample, a special cam arrangement was provided to separate the plates after the test. The spacings between the plates were indicated by a scale consisting of ruled hori-

1 Federal Specification R R-S-366a. 


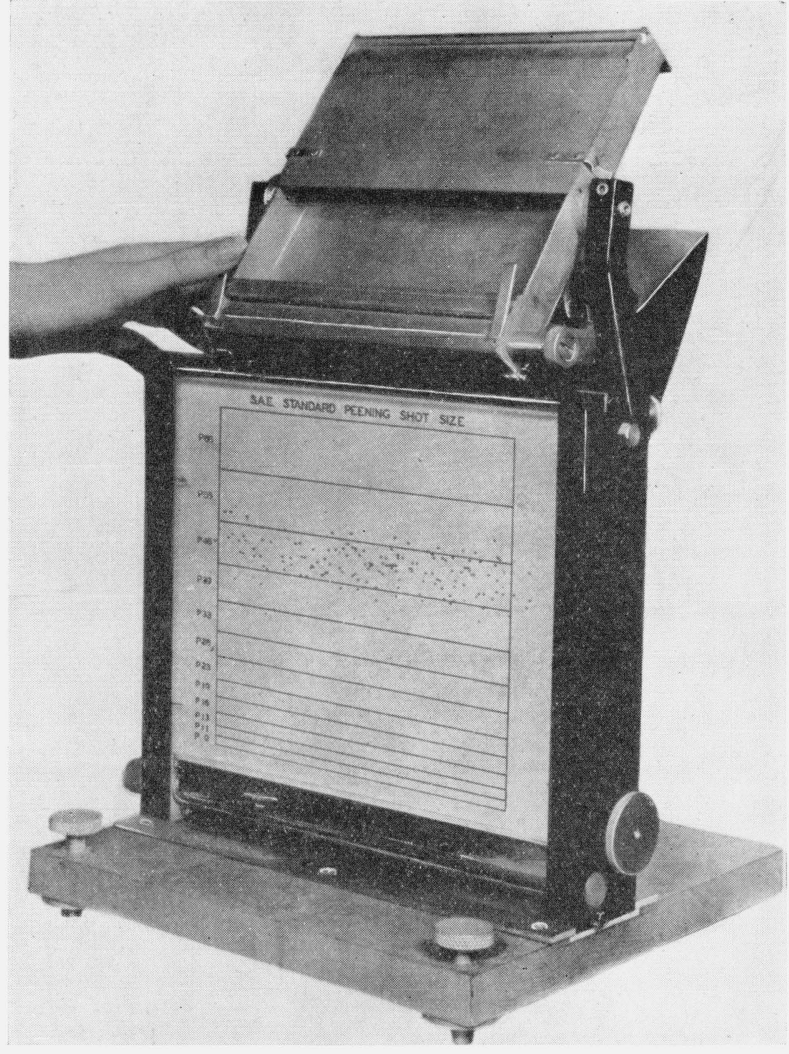

FIgURe 1. Mattson apparatus for determining size and distribution of peening shot.

zontal lines on the front plate. However, for these tests, an auxiliary transparent plate, ruled every $2 \mathrm{~mm}$, was attached to the front plate of the apparatus. The back plate was held against the wedges by springs.

The sample splitter consisted of a tilting table from which half of the sample could be removed into a container behind the apparatus. The sample can be halved as many times as necessary to obtain the required amount of material. Tilting the table forward prepared the remaining sample for the next division or for dropping the grains into the wedge-shaped space of the apparatus.

\section{Materials}

The samples of peening and cleaning shot that were furnished by the General Motors Corporation consisted of spherical iron particles of sizes commonly used in peening and metal-cleaning operations.

The three sands used in this study were chosen on the basis of their shape characteristics. The sands were separated by sieves, and the portion passing a No. 20 and retained on a No. 30 sieve was used. The Ottawa sand was that commonly used in testing portland cement (Federal Specification SS-C-158b). The river sand consisted of particles that had been worn smooth but were not as equidimensional as the Ottawa sand. The crushed limestone particles were angular and somewhat flaky.

\section{Scope}

In order to determine the characteristics of the Mattson apparatus, measurements were made of the apparent diameter of individual peening shot and sand particles, the reproducibility of results obtained in retesting the same particles, the effect of the size of sample on particle interference, and the effectiveness of the sample splitter. The apparatus was used for size measurements of a number of samples of peening and cleaning shot. Microscopic measurements were made, and weights were determined of individual particles in order to compare the diameter values determined by different methods. Tests were made by means of the Mattson apparatus on samples of two sands and a crushed limestone passing a No. 20 and retained on a No. 30 screen in order to evaluate the shape factor of these materials.

\section{Tests and Test Results}

\section{Measurements of Individual Particles}

(a) Mattson Apparatus

Measurements were made to the nearest $1 / 2 \mathrm{~mm}$ of the position of individual particles dropped into the apparatus a number of times. From the position in the apparatus, the apparent or effective diameter of the peening shot or sand particle was determined to the nearest $0.005 \mathrm{~mm}$. Twenty separate determinations were made on each of the 12 peening shot and 8 sand grains illustrated in figure 2 .

\section{(b) Microscopic Measurements}

Microscopic measurements were also made of the maximum and minimum diameters of the particles. Each particle was shifted with a probe after each pair of measurements. The maximum and minimum values of the series of 10 measurements on each particle are reported. 
(c) Microweighings

The weights of the individual particles were determined by means of a microbalance and were reported to $0.001 \mathrm{mg}$. The calculated diameters (assuming a spherical shape) are based on the specific gravity of larger quantities of materials determined by a picnometer method. The results of measurements and calculations are presented in table 1.

TABLE 1. Diameters of individual particles as determined by the Mattson apparatus, microscope, and as calculated from the weights

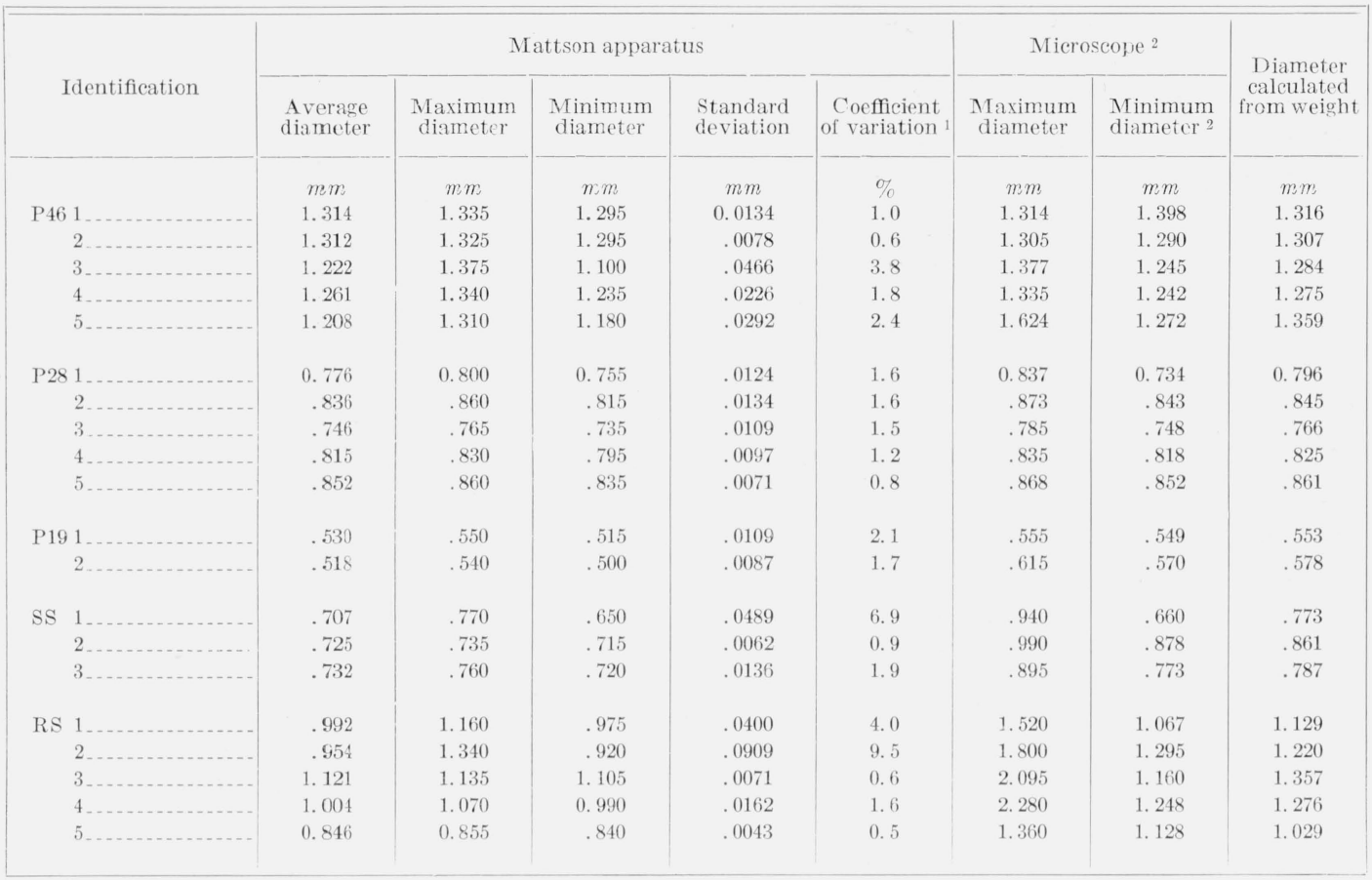

1 Based on 20 measurements of each particle.

2 Based on 10 measurements of each particle.

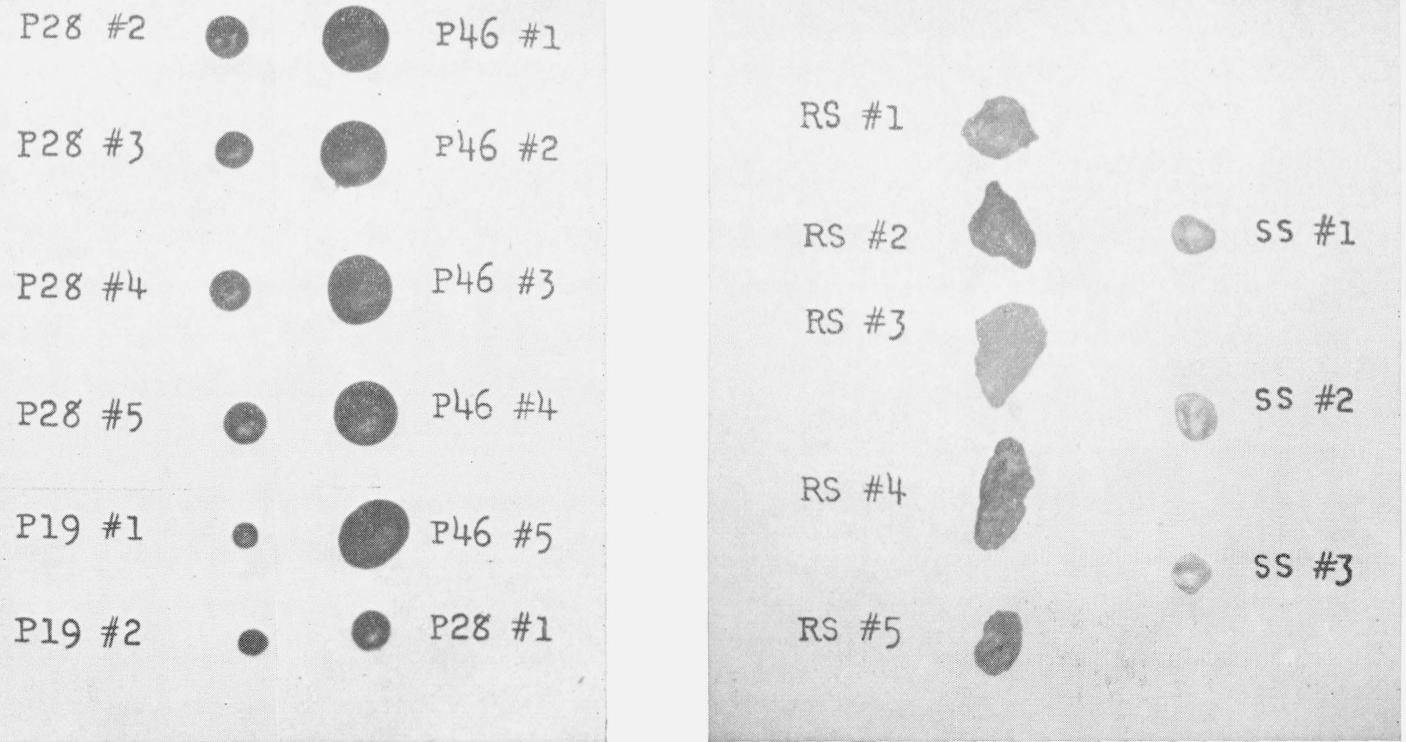

Figure 2. Individual shot and sand particles. 


\section{Repeated Tests on Same Materials}

(a) Peening Shot

Approximately 90 P46 peening shot were separated from a larger sample with the sample splitter. The shot were then dropped into the wedge-shaped space and measurements made to the nearest $1 / 2 \mathrm{~mm}$ of the positions of the individual particles. The shot were recovered and the test repeated a total of 10 times. The average diameter $(\Sigma n d / \Sigma n)$ and the number of shot smaller than or larger than certain arbitrary sizes were determined for each set of measurements and are presented in table 2 .

TABLE 2. Repeated tests on the same sample of 90 P46 shot

\begin{tabular}{|c|c|c|c|c|c|c|c|}
\hline & \multirow{2}{*}{$\begin{array}{l}\text { A ver- } \\
\text { age } \\
\text { diame- } \\
\text { ter }\end{array}$} & \multicolumn{3}{|c|}{$\begin{array}{l}\text { Number of shot } \\
\text { larger than- }\end{array}$} & \multicolumn{3}{|c|}{$\begin{array}{l}\text { Number of shot } \\
\text { smaller than- }\end{array}$} \\
\hline & & $\begin{array}{l}1.350 \\
\mathrm{~mm}\end{array}$ & $\begin{array}{l}1.325 \\
\mathrm{~mm}\end{array}$ & $\begin{array}{l}1.300 \\
\mathrm{~mm}\end{array}$ & $\begin{array}{l}1.175 \\
\mathrm{~mm}\end{array}$ & $\begin{array}{l}1.200 \\
\mathrm{~mm}\end{array}$ & $\begin{array}{l}1.225 \\
\mathrm{~mm}\end{array}$ \\
\hline & $\mathrm{mm}$ & & & & & & \\
\hline & 1. 270 & 4 & 14 & 27 & 1 & 13 & 18 \\
\hline & 1. 268 & 7 & 17 & 31 & 0 & 8 & 18 \\
\hline & 1. 267 & 3 & 14 & 27 & 1 & 16 & 23 \\
\hline & 1. 266 & 4 & 15 & 25 & 1 & 16 & 22 \\
\hline & 1. 262 & 4 & 13 & 21 & 1 & 14 & 21 \\
\hline & 1. 274 & 5 & 18 & 30 & 1 & 9 & 19 \\
\hline & 1. 266 & 6 & 12 & 24 & 3 & 14 & 23 \\
\hline & 1. 266 & 5 & 13 & 30 & 1 & 10 & 20 \\
\hline & 1. 267 & 3 & 16 & 28 & 1 & 17 & 26 \\
\hline & 1. 264 & 5 & 12 & 27 & 1 & 17 & 24 \\
\hline A verage. . & 1. 267 & 4. 6 & 14.4 & 27 & 1.1 & 13.4 & 21.4 \\
\hline Standard deviation. & 0.0033 & 1.3 & 2.1 & 3.1 & 0.54 & 3.3 & 2.7 \\
\hline $\begin{array}{l}\text { Coefficient of varia- } \\
\text { tion }(\%)\end{array}$ & .3 & 28 & 15 & 11 & 49 & 25 & 13 \\
\hline
\end{tabular}

(b) Ottowa Sand

A similar series of tests was made on a sample of the Ottawa sand. A 20-g sample was split seven times, and the particle-size distribution was determined. The test was repeated a total of 10 times, a new sample being used for each test. The average diameter and number of particles larger and smaller than certain arbitrary diameters are presented in table 3 .

\section{Interference of Particles}

Tests were made to study the possible interference of particles with each other in dropping to their positions in the wedge. Fifty-gram sam-
TABle 3. Ten samples of $20 \mathrm{~g}$ of Standard Ottawa sand (20 to 30 mesh), split 7 times

\begin{tabular}{|c|c|c|c|c|c|c|}
\hline & \multirow{2}{*}{$\begin{array}{l}\text { Aver- } \\
\text { age di- } \\
\text { ameter }\end{array}$} & \multirow{2}{*}{$\begin{array}{l}\text { Num- } \\
\text { ber of } \\
\text { par- } \\
\text { ticles }\end{array}$} & \multicolumn{2}{|c|}{$\begin{array}{l}\text { Number of } \\
\text { particles } \\
\text { greater } \\
\text { than- }\end{array}$} & \multicolumn{2}{|c|}{$\begin{array}{c}\text { Number of } \\
\text { particles } \\
\text { smaller } \\
\text { than- }\end{array}$} \\
\hline & & & $\begin{array}{c}0.750 \\
\mathrm{~mm}\end{array}$ & $\begin{array}{c}0.650 \\
\mathrm{~mm}\end{array}$ & $\begin{array}{c}0.450 \\
\mathrm{~mm}\end{array}$ & $\begin{array}{c}0.550 \\
\mathrm{~mm}\end{array}$ \\
\hline & $m m$ & & & & & \\
\hline & 0.643 & 261 & 24 & 130 & 3 & 33 \\
\hline & .644 & 265 & 27 & 130 & 1 & 33 \\
\hline & .643 & 243 & 17 & 116 & 2 & 22 \\
\hline & .641 & 237 & 27 & 113 & 4 & 37 \\
\hline & .638 & 248 & 22 & 111 & 2 & 32 \\
\hline & .647 & 223 & 21 & 112 & 1 & 29 \\
\hline & .644 & 239 & 21 & 119 & 2 & 30 \\
\hline & .639 & 241 & 26 & 108 & 5 & 31 \\
\hline & .640 & 256 & 25 & 121 & 4 & 42 \\
\hline & .642 & 245 & 16 & 124 & 3 & 31 \\
\hline Average.... & .642 & 246 & 22.6 & 118 & 2.7 & 32 \\
\hline Standard deviation ....... & .003 & 11.5 & 3.9 & 7.8 & 1.3 & 5.2 \\
\hline Coefficient of variation (\%) & .4 & 4.7 & 17 & 7 & 48 & 16 \\
\hline
\end{tabular}

ples of P46 shot were split four, five, six, and seven times, giving a considerable range in the number of particles measured in the different tests. The particle-size distribution was determined as in previous tests. Each of the values presented in table 4 is the average of two determinations.

TABLE 4. Effect of size of sample on average effective diameter of shot

\begin{tabular}{|c|c|c|c|}
\hline Number of times sample was split & $\begin{array}{l}\text { Number } \\
\text { of par- } \\
\text { ticles }\end{array}$ & $\begin{array}{l}\text { Average } \\
\text { diameter }\end{array}$ & $\begin{array}{c}\text { Difference } \\
\text { from grand } \\
\text { average }\end{array}$ \\
\hline $\begin{array}{l}4 \\
5 \\
6\end{array}$ & $\begin{array}{r}373 \\
190 \\
114 \\
50\end{array}$ & $\begin{array}{c}m m \\
1.280 \\
1.271 \\
1.267 \\
1.280\end{array}$ & $\begin{array}{c}m m \\
+0.006 \\
-.003 \\
-.007 \\
+.006\end{array}$ \\
\hline
\end{tabular}

\section{Tests of Peening and Cleaning Shot}

The particle-size distribution of a number of samples of peening and cleaning shot of a number of grades was determined. The size distributions are presented in figure 3 . The various statistical diameters computed from the size-distribution values are presented in table 5, together with the diameters computed from the weight of lots of 1,000 shot, assuming spherical shape. 


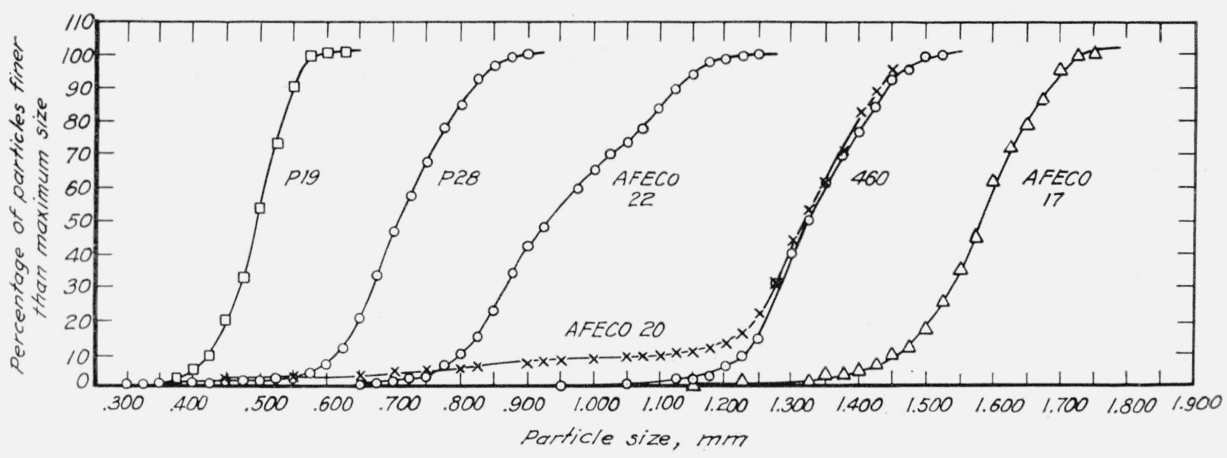

Figure 3. Percentage of particles of different samples of peening and cleaning shot finer than given sizes.

Determinations made by means of Mattson apparatus.

TABLE 5. Shape factor and diameter of peening shot as calculated by various formulas

\begin{tabular}{|c|c|c|c|c|c|c|c|}
\hline Identification & $\begin{array}{c}\text { Specific } \\
\text { grav- } \\
\text { ity }\end{array}$ & $\begin{array}{l}\text { A ver- } \\
\text { age di- } \\
\text { ameter } \\
\text { from } \\
\text { weight }\end{array}$ & ${ }^{1} d_{a v}$ & ${ }^{2} d_{e}$ & ${ }^{3} d_{v}$ & ${ }^{4} d_{w}$ & $\begin{array}{l}\text { Shape } \\
\text { fac- } \\
\text { tor } 5\end{array}$ \\
\hline & $g / m l$ & $m m$ & $\mathrm{~mm}$ & $\mathrm{~mm}$ & $m m$ & $m m$ & \\
\hline P28. & 7. 54 & 0.776 & 0.714 & 0.723 & 0.740 & 0.740 & 0.604 \\
\hline P46 ... & 7. 48 & 1. 308 & 1. 307 & 1. 242 & 1. 274 & 1. 279 & .567 \\
\hline No. $460 \ldots$ & 7. 11 & 1. 348 & 1. 375 & 1.301 & 1. 338 & 1. 345 & .534 \\
\hline No. $20 \ldots \ldots$ & 7.16 & 1. 350 & 1. 274 & 1. 305 & 1. 309 & 1. 323 & .576 \\
\hline No. $22 \ldots . .$. & 7.56 & 1. 005 & 0.952 & 0.969 & 0.970 & 1.002 & .582 \\
\hline No. 19 & 7.46 & 0.555 & .482 & .488 & .488 & 0.499 & .766 \\
\hline No. $17 \ldots$ & 7. 53 & 1. 615 & 1. 574 & 1. 597 & 1. 545 & 1. 732 & .600 \\
\hline
\end{tabular}

$1 d_{a v}=\Sigma n d / \Sigma n$.

$2 d_{e}=\Sigma n d^{2} / \Sigma n d$.

${ }^{3} d_{v}=3 \sqrt{\Sigma n d^{3 / \Sigma} n}$.

${ }^{4} d_{w}=\Sigma n d^{4} / \Sigma n d^{3}$.

${ }^{5}$ Shape factor $=1 / \rho N d_{v}{ }^{3}$.

$n=$ number of particles per group.

$d=$ mean of limits of group.

$\rho=$ specific gravity, $\mathrm{g} / \mathrm{ml}$.

$N=$ number of particles per gram.

\section{Shape Factor}

Tests were made of the apparent size-frequency distribution of materials of different shape factors. The P28 shot, Ottawa sand, river sand, and crushed limestone all passed the No. 20 sieve $(0.84 \mathrm{~mm})$ and were retained on the No. 30 sieve $(0.59 \mathrm{~mm})$. Of these materials, the peening shot were most nearly spherical; the Ottawa sand was rather rough but fairly well rounded. The river sand had some rather flat, semirounded particles, whereas the crushed limestone had sharp edges and corners and was composed mostly of flat particles. The size-frequency distribution curves are presented in figure 4 , and the various statistical diameters are presented in table 6 .
TABLE 6. Shape factors and diameter of particles as calculated by various formulas

\begin{tabular}{|c|c|c|c|c|c|c|c|}
\hline Identification & $\begin{array}{l}\text { Specific } \\
\text { gravity }\end{array}$ & $\begin{array}{c}\text { A verage } \\
\text { diameter } \\
\text { calcu- } \\
\text { lated } \\
\text { from } \\
\text { weight }\end{array}$ & ${ }^{1} d_{a v}$ & $d_{e}$ & $d_{*}$ & $d_{w}$ & $\begin{array}{l}\text { Shape } \\
\text { factor }\end{array}$ \\
\hline P28 shot.... & $\begin{array}{r}g / m l \\
7.54\end{array}$ & $\begin{array}{c}m m \\
0.776\end{array}$ & $\begin{array}{c}m m \\
0.714\end{array}$ & $\begin{array}{c}m m \\
0.723\end{array}$ & $\begin{array}{c}m m \\
0.740\end{array}$ & $\begin{array}{c}m m \\
0.740\end{array}$ & 0.604 \\
\hline Ottawa sand. & 2. 65 & .807 & .642 & .652 & .652 & .672 & .992 \\
\hline River sand & 2. 62 & .752 & .551 & .570 & .570 & .608 & 1. 21 \\
\hline Limestone... & 2. 70 & .801 & .482 & .524 & .521 & .593 & 1.90 \\
\hline
\end{tabular}

1 See table 5 for symbol notation.



Figure 4. Particle-size distribution as determined by the Mattson apparatus of 20- to 30-mesh shot, Ottawa sand, river sand, and crushed limestone.

Dashed lines indicate nominal openings of No. 20 and No. 30 sieves. O, P28 shot; $X, 20$ to 30 Ottawa sand; river sand; $\triangle$, screened limestone, 20 to 30 .

\section{Sample Splitter}

A series of tests were made in which a sample of P46 shot was split six times and tested in the Mattson apparatus. The weight of the final sample was compared with the weight of the sample before splitting. The remaining portion 
of the sample from the first test was used for the second test and the remainder from the second, for the third, etc. This process was repeated for 10 successive determinations. The average diameter of the 10 successive determinations, together with the percentage by weight of each sample remaining after splitting six times, is presented in table 7. Other tests were made in which the number of particles remaining after splitting a definite number of times was counted. These also served to indicate the efficiency of the sample splitter. Where the weight was not determined directly, the weight of 1,000 particles was used to compute the average weight per particle, and the weight of the split sample was computed from this value.

TABLE 7. Average diameter of particles and percentage by weight of particles remaining after splitting six times

Each test was made on the material remaining after previous tests.

\begin{tabular}{|c|c|c|}
\hline Test number & $\begin{array}{l}\text { Average } \\
\text { diameter }\end{array}$ & $\begin{array}{l}\text { Percentage } \\
\text { by weight } \\
\text { of particles } \\
\text { remaining } \\
\text { after split- } \\
\text { ting } 6 \text { times }\end{array}$ \\
\hline $1 \ldots$ & $\begin{array}{c}m m \\
1.271\end{array}$ & 2. 02 \\
\hline $2 \ldots$ & 1. 269 & 1. 92 \\
\hline $3 \ldots$ & 1. 270 & 2. 02 \\
\hline $4 \ldots$ & 1. 265 & 1.97 \\
\hline & 1. 276 & 1.84 \\
\hline $6 \ldots$ & 1. 263 & 2. 10 \\
\hline $7 \ldots$ & 1. 261 & 1. 76 \\
\hline $8 \ldots$ & 1. 274 & 1. 63 \\
\hline 9 & 1. 265 & 1. 61 \\
\hline $10 \ldots \ldots$ & 1. 265 & 1. 75 \\
\hline
\end{tabular}

\section{Discussion}

\section{Size of Particles Determined by Different Methods}

The shape of the particles measured and the method of measurement usually influence the final results. For example, in microscopic measurements, irregularly shaped or flat particles tend to assume their most stable position when placed on a microscope slide and the two larger of their three dimensions are observed. Repeated measurements made according to the methods of Feret or Martin of the diameter of an irregularly shaped particle adjusted to a new position before each measurement would yield a variety of values with a calculable (statistical) mean and standard devi- ation. Similarly, individual particles dropped in to the wedge-shaped space of the Mattson apparatus do not always exhibit the same effective diameter. It may be noted in table 1 that the standard deviation values of the measured diameters of individual particles were quite large, and
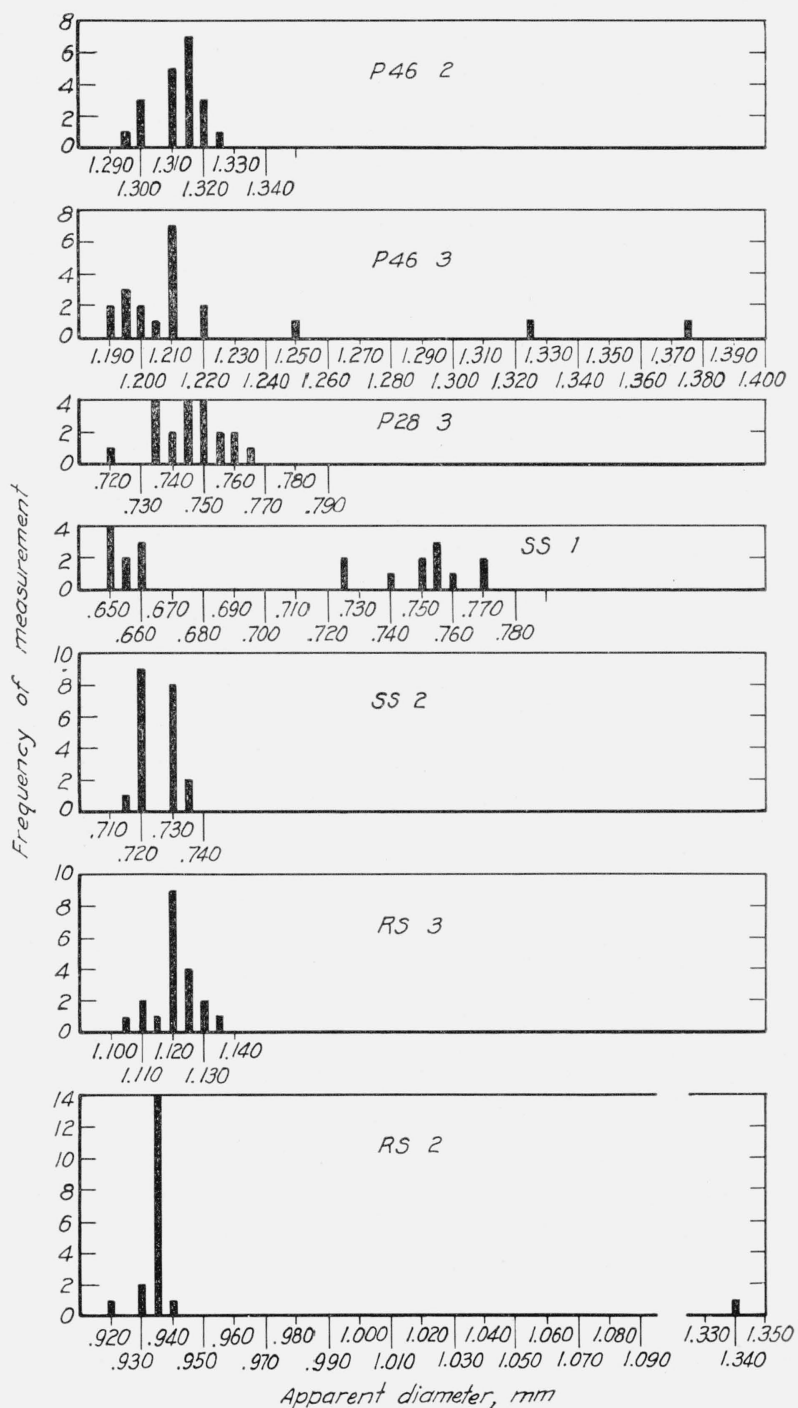

FIGURE 5. Effective diameter values of individual particles tested 20 times with the Mattson apparatus.

these values differed for different particles. The nature of these variations may also be noted in figure 5, which shows the measurement-distribution patterns of some typical particles. As may be noted, the patterns range from a rather close distribution diagram as in RS 2 , to a skewed distribution as in P46 3, and to a bimodal distribution for SS 1. The average values for the ratio of the 
mean microscopic diameter to the average diameter determined by the Mattson apparatus were $1.05,1.16$, and 1.52 for the peening shot, Ottawa sand, and river sand, respectively.

It is considered significant that the coefficient of variation values of the peening shot were approximately the same as the majority of the values for the Ottawa-sand and river-sand particles, which are not so equidimensional. It may be noted in table 1 and figure 6 that the average diameters of the individual particles determined by the Mattson apparatus were usually smaller than those calculated from the microweighings of the individual

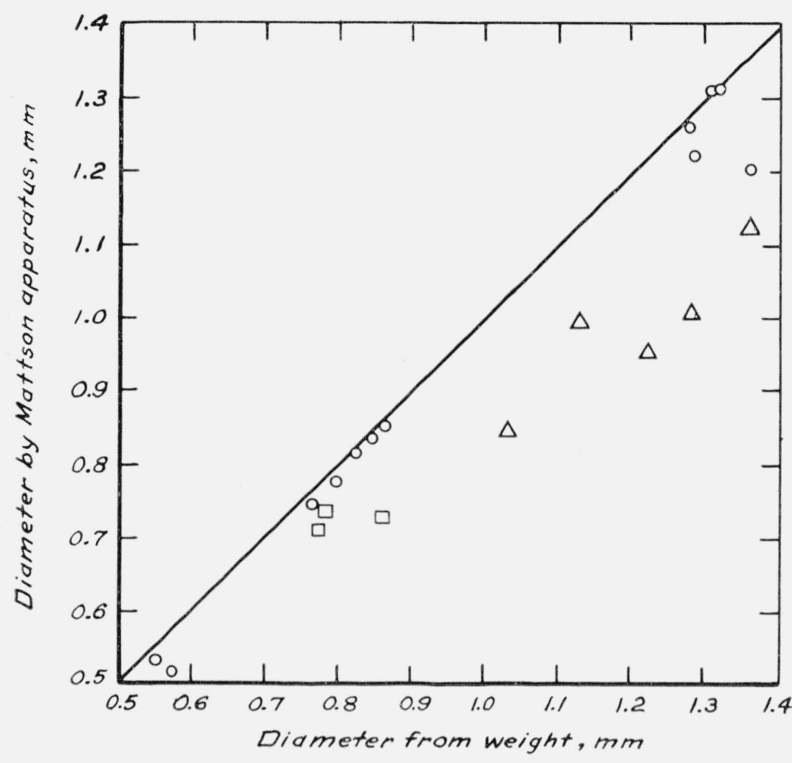

Figure 6. Relation of average diameter as determined by the Mattson apparatus to that determined from microweights of individual particles.

\section{$O$, Shot; $\square$, Ottawa sand; $\triangle$, river sand.}

particles. This was more apparent with the sands than with the peening shot. The average of mean diameters of peening shot as determined by the Mattson apparatus was 96.6 percent of that determined by microweighings, whereas for Ottawa sand the value was 89.6 percent and for river sand, 84.1 percent. The diameter calculated from the microweighings was usually between the maximum- and minimum-diameter values determined by the microscope. However, for the sand particles it was smaller for three of the eight particles measured.

The arithmetic mean diameter of a sample of irregularly shaped particles is not the same as the mean diameter based on volume or weight. Perrott and Kinney, ${ }^{2}$ Green, ${ }^{3}$ and Dalla Valle ${ }^{4}$ have indicated the necessity for giving proper weight to the various sizes in a sample and have presented formulas for calculating the "mean volume diameter" and "weight mean diameter" from the measured diameters. These formulas and the calculated diameters are given in tables 5 and 6.

\section{Shape Factors}

Dalla Valle (see footnote 4) has shown that a value for the shape of the particles may be calculated from the mean volume diameter, the number of particles per unit weight, and the density, as given in the formula in tables 5 and 6 .

The fact that the Mattson apparatus tends to indicate the smaller of three dimensions of flator disk-shaped particles makes possible an evaluation of the shape factor of particles when used in conjunction with sieves. The effect of the shape of the particles when testing four different 20to 30-mesh materials with the Mattson apparatus is evident in figure 4. The factor calculated from the number of particles per gram, the specific gravity, and the average volume diameter, $d_{v}$, according to the Dalla Valle formula (see footnote 4 ), results in values ranging from 0.534 for one sample of shot to 1.90 for the crushed limestone. It has been shown by Martin ${ }^{5}$ that this value is less than $\pi / 6$, or 0.524 , when computed from microscopic measurements. The shape factors of the peening shot were all slightly larger than $\pi / 6$, or 0.524 , but not as large as the values for Ottawa sand, river sand, or the crushed limestone. Microscopic examination and the measurements listed in table 1 indicated that the shot were not perfect spheres.

\section{Variations in Effective Diameter}

The variations of the effective diameter of individual particles may be expected to cause variations in the calculated average diameter of groups of particles. The standard-deviation values of the individual $\mathrm{P} 46$ shot in table 1 were from 2 to 14 times as great as the value for the group of 90 shot of table 2 . For the Ottawa sand,

\footnotetext{
2 G. Perrott and S. P. Kinney, J. Am. Ceram. Soc. 6, 417 (1923).

${ }^{3}$ H. Green, J. Franklin Inst. 204, 713 (1927).

4 J. M. Dalla Valle, Micromeritics, 2d ed. (Pitman Pub. Co., New York, N. Y., 1943).

5 Martin, Trans. Brit. Ceram. Soc. 23, 61 (1923).
} 
the individual values in table 1 were from 2 to 16 times the group values in table 3 .

The determination of the size distribution of a large number of particles in a sample is somewhat tedious. The possibility of starting with a definite weight sample, splitting a given number of times, and counting only the number of particles larger or smaller than certain limits was considered as a specification test. The number of particles per group varied more at the ends of the distribution curves than in the center, as indicated by the coefficient of variation values in tables 2 and 3 .

\section{Variations Due to Sample Splitter}

Certain variations also occurred in splitting the sample, as indicated in table 7. Theoretically, 1.56 percent of the particles should remain after splitting six times, but the data in table 7 indicate that as much as 2.10 percent of the particle remained. Other indications of the variations of the sample splitter were obtained from counts of particles of duplicate tests on the same material The computed weight of the test sample was usually 10 to 20 percent greater than it should have been. This was probably caused by the design or construction of the sample splitter itself and could possibly be remedied by placing the separators symetrically, by increasing the number of separating fins, or by proper placing of baffles.

There was no evidence, however, that any particular size of particles was removed. For example, as shown in table 4 , the average diameier determined in any one test does not differ from the grand average by as much as three times the standard deviation, commonly considered significant. The data in this table indicate that a rather wide range of sample size may be used in the calculations of the average diameter. The smaller sample of 50 shot appears to define satisfactorily the average size and is about the minimum required to indicate the type of distribution of a sample of shot. It would be preferable to use a sample of this size in order to reduce the number of measurements.

\section{Limitations of Testing Smaller Sizes}

The determination of the particle-size distribution of the smaller sizes, such as the P19 shot, was more difficult than with the larger sizes. Even with the use of a reading glass it was difficult to count the particles in any size group when the particles were from 0.25 to $0.50 \mathrm{~mm}$ in diameter.

\section{Conclusions}

The Mattson apparatus offers a rapid, visual method of determining the size and distribution of closely sized particles, such as peening shot, cleaning shot, and sand. More accurate evaluation of the average size and variations about this average can be made by determining the number of particles of each size grouping. The average diameter values calculated from these distributions are quite reproducible.

The diameter of irregular or flat particles as determined with the Mattson apparatus is a "statistical" diameter that is usually less than that determined by a microscope. This feature enables a determination of the shape factor of particles to be made when the apparatus is used with closely sized sieve fractions.

Washington, June 3, 1948. 